\title{
La acción colectiva en Argentina: actores, demandas y formas de lucha desde el retorno democrático
} Collective action in Argentina: Actors, demands
and forms of struggle since the democratic return

Leandro Gamallo*

\author{
D.R. (C) 2019. Perfiles Latinoamericanos \\ Licencia Creative Commons Atribución-NoComercial- \\ SinDerivar (CC BY-NC-ND) 4.0 Internacional \\ Perfiles Latinoamericanos, 28(55) | 2020 \\ DOI: $10.18504 / \mathrm{pl} 2855-004-2020$ \\ Recibido: 30 de marzo de 2018 \\ Aceptado: 11 de octubre de 2018
}

\section{Resumen}

Este artículo presenta una breve historia de la conflictividad social en Argentina del periodo 1989-2017. La evolución de los conflictos sociales se indaga a partir del análisis dinámico de la acción colectiva en su relación con los procesos políticos. Se trabaja en particular con tres de sus dimensiones: los actores contenciosos, las demandas principales que estos enuncian, y las formas de lucha llevadas a cabo. A nivel general, se muestra el proceso hacia la heterogeneidad de la acción colectiva y un impacto creciente de los conflictos en el desarrollo de la política institucional.

Palabras clave: acción colectiva, conflictos sociales, movimientos sociales, Argentina, procesos políticos.

\begin{abstract}
This article presents a brief history of social conflict in Argentina for the period 1989-2017. The evolution of social conflicts are investigated based on the dynamic analysis of collective action in its relation with political processes. In particular, we will work with three of the dimensions that make them up: the contentious actors, the main demands they enunciate, and the forms of struggle carried out. At a general level, a process of diversification of collective action and a growing impact of conflicts on the development of institutional policy is shown.
\end{abstract}

Keywords: Collective action, social conflicts, social movements, Argentina, political processes.

* Doctor en Ciencias Sociales por la Universidad de Buenos Aires (Argentina). Becario posdoctoral del CONICET con sede en el Instituto de Investigaciones Gino Germani, Universidad de Buenos Aires | leandrogamallo@gmail.com 


\section{Introducción}

E

ste artículo presenta una breve historia de la conflictividad social en $\mathrm{Ar}-$ gentina del periodo 1989-2017. La evolución de los conflictos sociales se indagará a partir del análisis dinámico de la acción colectiva, en específico, de tres de las dimensiones que la conforman: los actores contenciosos, las demandas principales que estos enuncian, y las formas de lucha llevadas a cabo. Por acción colectiva entenderemos "episodios que comprometen a participantes que no actúan juntos de modo rutinario y/o que emplean medios de acción distintos que adoptan para la interacción cotidiana” (Tilly, 2000, p. 10). En este sentido, la acción colectiva es, por definición, "discontinua y contenciosa: no está construida sobre rutinas diarias y tiene implicancias para los intereses de personas distintas al grupo que actúa, así como para los propios intereses compartidos de los actores" (Tilly, 2000, p. 10).

El análisis de las transformaciones de los actores, demandas y formas de la acción colectiva en Argentina se pondrá en relación con las dinámicas de los procesos político-institucionales, ${ }^{1}$ y en menor medida con los distintos modos de desarrollo económico. ${ }^{2}$ Por esta razón, el enfoque teórico de la acción colectiva que más se ajusta a nuestros objetivos es el de las "oportunidades políticas" (Tilly, 1978; Tarrow, 1997, entre otros), dado que dicho enfoque entiende los procesos de movilización en relación con las disputas institucionales y los cambios en la política estatal. Sin embargo, también tendremos en cuenta los aportes de las teorías de la movilización de recursos y de los llamados procesos enmarcadores para analizar la evolución de las tácticas y formas de organización de los movimientos sociales, así como la conformación o disolución de identidades sociales, culturales y políticas en los procesos contenciosos. ${ }^{3}$

1 Algunos de los elementos para evaluar los cambios en el sistema político serán el grado de apertura relativo de las instituciones políticas, la estabilidad o inestabilidad de las élites gobernantes, la presencia o ausencia de alianzas en las élites, y la capacidad del Estado y su propensión a la represión (McAdam, 1999).

2 El modo de desarrollo puede definirse como "la forma en la que se acumula y se reproduce el capital en momento y un país determinados, teniendo en cuenta que dicha forma particular se configura a partir de las luchas de intereses y las presiones de las distintas clases sociales sobre el Estado" (Cantamutto \& Costantino, 2016, p. 16).

3 Según McAdam et al. (1999), las tres principales corrientes teóricas de los movimientos sociales son la teoría de las oportunidades políticas, la teoría de las estructuras de movilización (o movilización de recursos), y la teoría de los procesos enmarcadores (o identidades). Aquí se sostiene con dichos autores que tales teorías confluyen en una "síntesis emergente" en la medida en que se trata de desarrollos teóricos que no rivalizan sino que se complementan. 
Como intentaremos demostrar a lo largo del análisis, estas tres grandes dimensiones (luchas sociales, procesos institucionales, y modelos de desarrollo económicos) no son tomadas de manera independiente entre sí, sino concebidas de forma interrelacionada, en consecuencia alteraciones drásticas en alguna provocarán cambios en las otras, sin que pueda sostenerse la primacía de una en particular sobre el resto. Dado que el objetivo del trabajo es describir el campo de la conflictividad, las transformaciones en la política institucional y los modelos macroeconómicos serán considerados en el análisis de manera parcial, como contexto de las luchas acaecidas en diversos momentos de la historia. Para hacerlo repasaremos investigaciones propias y de otros equipos de trabajo que han dado cuenta parcialmente de estas transformaciones con diversas metodologías: bases de datos de acciones contenciosas, entrevistas en profundidad a dirigentes sociales, etnografías sobre organizaciones políticas, sindicales, sociales, etcétera.

Se ha dividido la exposición según las distintas etapas de la historia reciente argentina. En primer lugar, se describen las mutaciones en el campo de la acción colectiva que se produjeron en los años noventa y el protagonismo de los movimientos sociales en la caída del neoliberalismo en Argentina hacia fines de 2001. En segundo, se analiza la recomposición económico-institucional posterior (2002) y la compleja relación entre el gobierno de Néstor Kirchner (2003-2007) y las organizaciones populares, algunas de las cuales asumieron un carácter oficialista y se incorporaron al gobierno. En tercer lugar, se desarrolla el campo de la conflictividad durante los mandatos de Cristina Fernández de Kirchner (2007-2015), en concreto la dinámica y los efectos de la confrontación de este gobierno con la burguesía agropecuaria. Por último, se dará cuenta de las luchas que se dieron en los dos primeros años (2015-2017) del gobierno de Mauricio Macri.

\section{Las luchas contra el neoliberalismo y su derrumbe (1989-2001)}

Con el golpe de Estado cívico-militar en 1976 se inauguró un ciclo de reformas que cambiaron irreversiblemente la estructura social, reemplazando el modelo de desarrollo previo por un patrón de acumulación de capital orientado fundamentalmente a la valorización financiera (Basualdo, 2011). Los efectos de largo plazo de las transformaciones que emprendió la última dictadura argentina (1976-1983) involucraron procesos como la desindustrialización de la economía y el predominio creciente del capital financiero; la reconversión del rol del Estado como mecanismo redistributivo, y la reconfiguración de la relación de fuerzas entre el capital y el trabajo, la cual se dio mediante un genocidio que dejó treinta mil militantes desaparecidos, la desarticulación polí- 
tica del movimiento obrero y un disciplinamiento generalizado del resto de la sociedad (Azpiazu, et al., 2004). El regreso democrático se produjo luego de la derrota de la dictadura en la guerra de Malvinas (1982) y a partir de las luchas de los sindicatos, partidos políticos y organismos de derechos humanos en los últimos años del régimen. Sin embargo, esta derrota política de la dictadura (evidenciada en el encarcelamiento de sus principales dirigentes por delitos de lesa humanidad tan solo unos años después) debe matizarse observando el éxito en las transformaciones de largo plazo. Estas implicaron mutaciones relevantes en las clases sociales y sus relaciones entre sí, de modo que se produjo un proceso de relativa homogeneización de los intereses de las distintas cúpulas empresarias y de heterogeneidad y fragmentación social y política de la clase obrera (Villarreal, 1985). Así, pues, la relativa uniformidad de la conflictividad social argentina nucleada en torno a la clásica disputa entre capitalistas y trabajadores se complejizó a medida que se transformaba la estructura social.

La descomposición del poder obrero articulado alrededor del movimiento sindical se vio fuertemente acelerada en los años noventa, cuando durante las presidencias del peronista Carlos Menem (1989-1999) se aplicaron políticas de corte neoliberal que impactaron con fuerza en las ramas más pequeñas y menos concentradas de la industria y sobre el poder adquisitivo de los trabajadores. Entre tales políticas destacaban la apertura comercial, la liberalización financiera, la regulación selectiva de mercados (rigidez del mercado cambiario y flexibilización del laboral, por ejemplo) y una ampliación de la refuncionalización del Estado basada en una amplia privatización de empresas de bienes y servicios públicos (Cantamutto \& Wainer, 2013). Este paquete de medidas se implementó luego de la aguda crisis económica de los años 1988-1990, la cual estuvo signada por una hiperinflación de consecuencias sociales devastadoras, como el aumento vertiginoso de la pobreza y la marginalidad social. ${ }^{4}$ Durante 1989 se dio una ola de saqueos de comercios inédita en la historia reciente argentina que ya prefiguraba las transformaciones en la acción colectiva de los sectores populares. Dichos saqueos no solo representaron formas de confrontación nuevas que desbordaban todos los canales de participación existentes, sino que exponían dramáticamente la "nueva cuestión social" argentina: la pobreza estructural de una porción importante de su población (Serulnikov, 2017).

El efecto más perdurable de la crisis hiperinflacionaria no sería el shock redistributivo generado por el permanente aumento de los precios, sino el impacto en la subjetividad de los trabajadores, los que apoyarían abiertamente las políticas neoliberales como medio supuestamente necesario para alcanzar la "estabilidad", un valor construido como hegemónico por el orden político de

4 El índice de inflación en 1989 fue de 3080\%, y en 1990 de 2313\% (Banco Mundial, 2018a). 
los años noventa (Muñoz, 2010). Como ha señalado Perry Anderson, "[...] hay un equivalente funcional al trauma de la dictadura militar como mecanismo para inducir democrática y no coercitivamente a un pueblo a aceptar las más drásticas políticas neoliberales. Este equivalente es la hiperinflación" (Anderson, 1997, p. 121). De modo que el núcleo de las reformas neoliberales en Argentina se procesó como la "solución" a la crisis de fines de los años ochenta. A pesar del indudable consenso construido - demostrado en las urnas en 1995, cuando Menem fue reelecto presidente con casi el 50\% de los votos-, muchas de las medidas encontraron una fuerte resistencia obrera y popular, sobre todo algunas privatizaciones de empresas emblemáticas. Las derrotas de los gremios ferroviarios y telefónicos en la lucha contra la privatización de sus empresas en los primeros años noventa son casos representativos que marcarían el destino del resto de los trabajadores (Bonnett, 2008).

Con un poder sindical en retroceso, tanto por las derrotas sufridas $-\mathrm{y}$ la alianza de algunas dirigencias gremiales con el gobierno- como por la desarticulación de su base social (desempleo, informalidad, tercerización, etc.), la conflictividad social de la época estuvo marcada por su diversificación: a) multiplicación de los actores contenciosos organizados de forma novedosa, b) aparición de demandas y reivindicaciones heterogéneas, y c) conformación de nuevas formas de lucha. En relación con los sujetos contenciosos, en el mundo sindical se consolidó la Central de Trabajadores de Argentina (СтA) en oposición a la tradicional y peronista Confederación General del Trabajo (CGT). Sin embargo, muchos de los conflictos más importantes de entonces fueron protagonizados por actores que tendrían un protagonismo inédito: "familiares y amigos" de víctimas de represión policial y/o abusos de poder, jubilados, movimientos de desocupados, organismos de derechos humanos, fábricas recuperadas por sus trabajadores, asambleas de vecinos, etc. Hacia fines de la década, el derrumbe del protagonismo sindical se correspondió con un mayor protagonismo del movimiento de desocupados y de organizaciones diversas de la sociedad civil: centros de estudiantes, organismos de derechos humanos, familiares y amigos de víctimas, vecinos, etcétera.

Muchos de estos colectivos se conformaron como respuesta a un daño particular y por fuera de las instituciones tradicionales de procesamiento de las demandas sociales. Muchos también proclamaron su autonomía, tanto respecto del Estado como de cualquier partido político o sindicato (aunque otros se inscribieron en tradiciones políticas como el peronismo o alguna vertiente del marxismo) y se organizaron bajo formas asamblearias y horizontales. Sus reivindicaciones eran heterogéneas e incluían aspectos "corporativos" (el aumento de jubilaciones o la extensión de planes de asistencia social para desempleados, etc.), "políticos" (el cambio de modelo económico, la renuncia de funcionarios, 
etc.) e "identitarios" (como el reconocimiento formal de las organizaciones). Estos nuevos actores recurrieron a performances de acción inusuales para acceder a demandas insatisfechas o resolver por sus propios medios problemas que el Estado no solucionaba. En esos años se expandió la acción directa, entendida como las "formas de acción contenciosa que no se encuentran mediadas por la institucionalidad dominante" (Pérez \& Rebón, 2012, p. 21). Así, los modos de manifestación de la protesta popular rebalsaron los canales clásicos de participación y se expresaron mediante modalidades disruptivas como cortes de calles y rutas, tomas de edificios, acampes y bloqueos, "escraches", 5 saqueos y estallidos (Auyero, 2002; Farinetti, 2000; Merklen, 2010; Antón et al., 2010).

Gráfico 1. Protestas por año, según tipo de organización en Argentina (1989-2003)

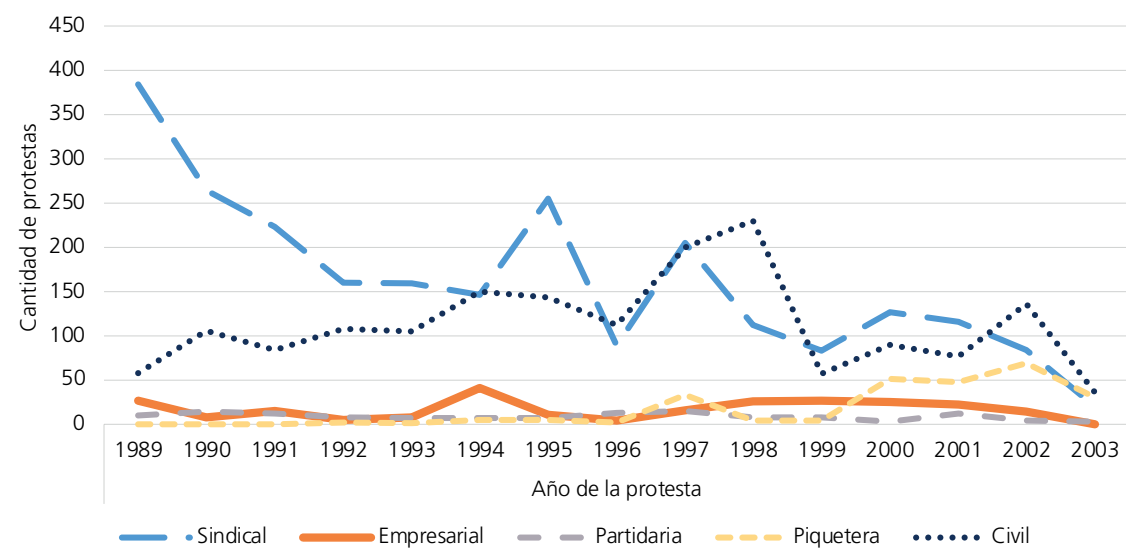

Nota: Para facilitar su lectura, se han expuesto las categorías principales; $\mathrm{N}=5268$

Fuente: Schuster et al. (2006, p. 36).

Al cambio de actores, demandas y formas de acción debe sumársele el desplazamiento del centro de los conflictos desde la ciudad de Buenos Aires hacia el "interior" del país. En concreto, el "estallido" de diciembre de 1993 en Santiago del Estero que demandaba el pago de sueldos a trabajadores estatales - y que involucró destrozos en edificios públicos y saqueos de las casas particulares de

5 Los escraches fueron performances colectivas creadas durante los años noventa por las organizaciones de derechos humanos en las que se "escrachaba" (es decir, se marcaba, señalaba o ponía en evidencia) a las viviendas o lugares de trabajo de los acusados de participar en delitos de lesa humanidad durante la última dictadura militar en Argentina que se encontraban en libertad. 
funcionarios de la provincia-y la "pueblada" de Cutral Co y Plaza Huincul, provincia de Neuquén — que incluyó el corte de la ruta Nacional 22 por varios días reclamando puestos de trabajo- conforman los hechos representativos de estas nuevas modalidades de la protesta porque contenían las formas contenciosas que serían emblemáticas durante toda la década: los estallidos violentos y los cortes de ruta o "piquetes" (Auyero, 2002; Farinetti, 2000). A estos dos hechos paradigmáticos se deben agregar las movilizaciones que demandaban justicia por la muerte de la adolescente María Soledad Morales en Catamarca en 1990. Las protestas — que promovieron las "marchas del silencio" para reclamar y resignificar la demanda de "justicia" y "lucha contra la impunidad"visibilizaron la trama corrupta en Catamarca y provocaron la destitución del entonces gobernador Ramón Saadi.

Estos novedosos procesos de organización dieron cauce a las resistencias populares frente al neoliberalismo conocidas como el nuevo repertorio de acción de los movimientos sociales argentinos (Auyero, 2002; Svampa \& Pereyra, 2003; Merklen, 2010). La importancia de estas transformaciones fue tal que muchas de estas dimensiones perduraron, aun cuando las condiciones políticas y económicas cambiaron años más tarde. En rigor, las nuevas formas de organización y lucha no reemplazaron a las viejas, sino que las complementaron. Tanto los estallidos y puebladas provinciales, como la expansión del movimiento de desocupados ("piqueteros") se asentaron sobre las experiencias previas de resistencia sindical que encontraron otros cauces de acción mediante formas organizativas superadoras (Auyero, 2002). Pero, además, estas mutaciones en el repertorio de acción colectiva no deben entenderse como un simple inventario empírico de acciones relativamente novedosas y más potentes que las anteriores, sino como nuevos modos de socialización y participación política. La clave de este fenómeno fue la conversión de la identidad trabajador hacia la de pobre (Merklen, 2010) o, dicho de otra manera, fueron hechos que llevaron el lugar de inscripción de las clases populares de la fábrica al barrio (Svampa, 2005). De esta manera, la "inscripción territorial" (o la "territorialización") operó como el factor más trascendente de "reafiliación” del universo popular, tras haberse perdido todas las referencias en el mundo del trabajo formal. Este tejido social en torno a la cooperación mutua — que muchas veces reemplazó de forma efectiva al Estado- se sedimentó en organizaciones político-sociales de fuerte anclaje territorial: el mundo piquetero. En consecuencia, las transformaciones en la contienda popular de los años noventa estuvieron relacionadas tanto con las urgencias de construir más y mejores herramientas para obtener recursos en un contexto de pauperización acelerada, como con la conformación de nuevas redes de contención y pertenencia que proporcionaran un anclaje identitario y colectivo a la participación popular. 
Todas estas transformaciones en la conflictividad social se aceleraron hacia finales de la década, cuando Argentina experimentó el agotamiento del modelo neoliberal y atravesó la peor crisis económica, social y política de su corta historia como nación. En 1999 asumió el gobierno Fernando de la Rúa, de Unión Cívica Radical, y él profundizó las medidas de ajuste fiscal y ortodoxia económica. Entre 1999 y 2002 la actividad económica se derrumbó casi un 20\% (Banco Mundial, 2018b), indicadores sociales como la pobreza y la desocupación empeoraron vertiginosamente, una profunda crisis política atravesó al conjunto del sistema de representación democrático durante esos años, ${ }^{6}$ y una intensa y beligerante conflictividad social se instaló en las calles de todo el país. A pesar de que en las provincias las protestas continuaron, el centro de las luchas volvió a ser Buenos Aires y su extensa periferia urbana, un área de más de diez millones de personas que concentra los principales bolsones argentinos de pobreza. Las resistencias de los distintos sectores afectados por las políticas neoliberales — fundamentalmente del movimiento piquetero_ - crecieron a medida que el agotamiento del modelo se evidenciaba más. Hacia fines de diciembre de 2001, en respuesta a distintas medidas gubernamentales para hacer frente al déficit fiscal y al abismo del default de la deuda externa, ${ }^{7}$ las protestas confluyeron en pedir la renuncia del ministro de Economía y, finalmente, la del propio presidente. Las jornadas del 19 y 20 de diciembre de $2001,{ }^{8}$ punto de inflexión en la historia reciente argentina, constituyeron el momento más agudo del ciclo de protestas iniciado años antes, en el que se manifestaron masivamente los sectores populares y medios con distintos reclamos, pero con una consigna en común: "Que se vayan todos".

Las movilizaciones, saqueos de comercios, cortes de calles y rutas, y enfrentamientos con las fuerzas de seguridad en todo el país terminaron con el gobierno de De la Rúa, e inauguraron una nueva etapa político-económica. A pesar del colapso inherente al propio modelo económico — que dio lugar a disputas al interior de la clase dominante sobre cómo sería su salida—, ${ }^{9}$ el cam-

6 En las elecciones legislativas de 2001, el 20\% de los electores votó en blanco o impugnó su sufragio, a este movimiento se le denominó el "voto bronca" contra el sistema político.

7 Las medidas más importantes incluyeron el recorte del 13\% al salario de los trabajadores estatales y de las jubilaciones, y la restricción de la disposición de dinero en efectivo de plazos fijos, cuentas corrientes y cajas de ahorros para evitar la salida de dinero de un sistema bancario al borde de la bancarrota.

8 Ante la incipiente ola de saqueos en todo el país, la noche del 19 de diciembre de 2001 Fernando de la Rúa anunció el estado de sitio, suspendiendo las garantías constitucionales. Esa misma noche millones de argentinos protagonizaron un "cacerolazo" (hacer ruido golpeando cacerolas o cualquier instrumento metálico) y se congregaron en los principales edificios públicos de todo el país. Al día siguiente, las protestas - movilizaciones, saqueos, cacerolazos, escraches en casas particulares de funcionarios, etc.se radicalizaron hasta que De la Rúa oficializó su renuncia por la noche. El saldo de la represión en distintas ciudades del país fue de 39 muertos.

9 Ante la encrucijada del agotamiento del modelo económico, los grupos más concentrados de la burguesía argentina se enfrentaron con aquellos que proponían dolarizar la economía y continuar con la 
bio político de principios del siglo XXI en Argentina no se comprende sin dar cuenta de las decisivas luchas populares para cerrar un patrón de acumulación que rigió al país durante veinticinco años. Los movimientos sociales señalaron el daño y las injusticias que producía el modelo neoliberal y actuaron para dinamitar sus consensos. Sin embargo, no superaron su propia fragmentación ni constituyeron alianzas estratégicas con otros actores para protagonizar una nueva etapa hegemónica en la Argentina (Muñoz, 2010; Retamozo, 2011). Ante la ausencia de alternativas provenientes del mundo de las organizaciones populares, la reconstrucción política tuvo que ser protagonizada por los actores "tradicionales", aunque sobre otras coordenadas político-simbólicas y otras relaciones de fuerzas entre la clase dominante y los sectores subalternos. Tras la renuncia de De la Rúa el 20 de diciembre de 2001 - y un interinato de cinco presidentes distintos en una semana- el peronista Eduardo Duhalde (ex candidato a presidente derrotado por De la Rúa en las elecciones de 1999) logró concitar el apoyo de la mayoría de su partido y fue proclamado presidente hasta terminar el mandato. Condicionado por las protestas, Duhalde comenzó por reconocer los daños producidos por el neoliberalismo y, por tanto, por aceptar la legitimidad de los reclamos. Entre otras medidas, Duhalde implementó el programa de ingreso masivo "Jefes y Jefas de Hogar Desocupados", que significó la cobertura de 150 pesos mensuales (50 USD) a casi dos millones de familias (Andrenacci, Ikei, Mecle \& Corvalán, 2005). Ante una sociedad con niveles de desempleo y pobreza inéditamente altos, ${ }^{10}$ la intervención del Estado se orientó a garantizar umbrales mínimos de subsistencia para los grupos sociales más desfavorecidos, y a neutralizar potenciales estallidos sociales (Perelmiter, 2012). De este modo, a pesar de no haber conducido la salida de la crisis, los movimientos sociales funcionaron como un condicionante de las políticas públicas y hasta de las propias dinámicas de la democracia representativa. Tras las repercusiones por el asesinato de dos militantes piqueteros el 26 de junio de 2002 a manos de la policía, en el marco de una manifestación por aumento en los subsidios de desempleo, Duhalde debió anticipar el llamado a elecciones y el traspaso de mando. El 27 de abril de 2003, el candidato apoyado por Duhalde, Néstor Kirchner, fue electo presidente con solo el 22\% de los votos, tras la renuncia de Carlos Menem (que había obtenido el 25\% de los votos) a la segunda vuelta electoral.

deflación (fundamentalmente el grupo de empresas privatizadas de servicios no transables) y aquellos que proponían devaluar la moneda. El ascenso de Duhalde al poder coronó a estos últimos en detrimento de los "dolarizadores" (Gaggero \& Wainer, 2004).

10 La pobreza alcanzó al 42.29\% de la población en octubre de 2002; mientras que el 16.92\% había caído en la indigencia (Arakaki, 2011). Los índices más altos desde que existen los indicadores estadísticos. 


\section{El primer kirchnerismo y los movimientos sociales (2003-2007)}

El gobierno de Kirchner consolidó un nuevo modo de desarrollo, cuyas piedras fundamentales había puesto el interinato de Duhalde. El neodesarrollismo ${ }^{11}$ (Cantamutto \& Costantino, 2016) aprovechó un ciclo económico ascendente sustentado en condiciones internacionales favorables para la exportación de commodities a fin de promover la expansión del mercado interno, la recuperación del poder adquisitivo entre porciones importantes de los trabajadores, y una mejora en diversos indicadores sociales como la desocupación, la pobreza, la desigualdad social, etc., aunque varias dimensiones solo alcanzaran los niveles previos a la crisis. Con una fuerte debilidad de origen por el poco porcentaje de votos obtenido, el gobierno comenzó a dar cauce a las diversas demandas de la sociedad civil, conformando alianzas políticas novedosas. A pesar de provenir del partido que llevó a cabo las reformas neoliberales en los años noventa, ${ }^{12}$ Kirchner desarrolló una retórica progresista que constituyó al Estado como el lugar de resolución de problemas sociales e integración social (Muñoz \& Retamozo, 2008) y ubicó como enemigos a los actores protagonistas de los gobiernos anteriores: el menemismo, la especulación financiera y los organismos multilaterales de crédito como el FMI y, más atrás, a la última dictadura cívico-militar. ${ }^{13}$

Desde el punto de vista del conflicto social, los cambios lentamente se hicieron evidentes. Durante los primeros años el actor más dinámico y con mayor poder de veto continuaba siendo el movimiento piquetero, que durante 2002 y 2003 superó en cantidad de acciones colectivas a las desarrolladas por el sindicalismo (Antón et al., 2010). El nuevo discurso oficial interpeló a un sector del movimiento, en particular a aquel que se reconocía dentro de la tradición nacional-popular del peronismo combativo de los años sesenta y setenta. Tanto por la afinidad ideológica de este sector, como por la táctica explícita del gobierno de construir alianzas con movimientos sociales afines, un grupo

11 Excede a los objetivos de este trabajo delimitar el modelo de desarrollo económico de la etapa. A grandes rasgos, el neodesarrollismo de los gobiernos kirchneristas se remonta a la teoría heterodoxa de Keynes, sosteniendo una mayor presencia regulatoria del Estado, una institucionalidad de las relaciones entre capital y trabajo, y la expansión de políticas sociales hacia el sector de la población que no puede ser absorbida por el mercado de trabajo formal. Por otra parte, el modelo neodesarrollista argentino ha promovido la actividad industrial como promotora del empleo y el impulso de actividades extractivas (agricultura y minería) sobre las cuales se redirecciona parte de la renta (Cantamutto \& Costantino, 2016).

12 Néstor Kirchner fue gobernador de Santa Cruz desde 1991 hasta 2003 por el Partido Justicialista. Aunque pertenecía al mismo partido que Menem, Kirchner se opuso a algunas de sus reformas.

13 Este desplazamiento ideológico se articuló con el denominado "giro a la izquierda" que experimentaron numerosos países de América Latina (Arditi, 2009). 
amplio de organizaciones (las de mayor cantidad de militantes y adherentes) se convirtieron en oficialistas y accedieron a cargos políticos en distintos niveles del Estado. Este hecho no solo fragmentó aún más al movimiento piquetero, sino que produjo cambios en los objetivos, tácticas de lucha y modos organizativos de las agrupaciones, ahora oficialistas, que concibieron su militancia social articulada a su trabajo en el Estado (Perelmiter, 2012). Además, se introdujo un tipo de acción colectiva poco frecuente hasta ese entonces: las movilizaciones para apoyar al gobierno o para demandar a actores adversarios del gobierno. Los gobiernos kirchneristas construyeron con estos sectores una base social contenciosa, utilizando en varias ocasiones el recurso de la protesta para confrontar a algunos actores del poder económico (Pérez \& Natalucci, 2010; Perelmiter, 2012).

Sin embargo, no todas las organizaciones piqueteras se involucraron con el discurso gubernamental. Un sector heterogéneo — que incluyó a fracciones del peronismo de izquierda, del marxismo tradicional y del autonomismomantuvo su oposición frontal hacia el Estado con las tácticas de la etapa anterior, fundamentalmente con los cortes y acampes callejeros. Si bien el gobierno desactivó la represión como forma de enfrentar los conflictos, aisló a este sector con relativo éxito no solo fragmentando las viejas alianzas, sino deslegitimando al movimiento piquetero y al piquete (el corte de calles) como forma de lucha característica de la etapa anterior y, por lo tanto, anacrónica. Como afirma cierta literatura especializada en movimientos sociales (McAdam et al., 1999), la presencia de un "ala radical" benefició al sector moderado en su rol "dialoguista" y mediador en los conflictos. No obstante, a pesar de la desintegración política, probablemente el movimiento de conjunto se benefició conteniendo a los dos sectores, dado que se alcanzaron objetivos específicos como la ampliación en el número de emprendimientos productivos, cooperativas y subsidios sociales financiados por el Estado (Perelmiter, 2012).

Por otra parte, la expansión sostenida del mercado interno hizo que se reincorporara de manera creciente a grandes contingentes de desempleados al mercado laboral, aunque muchos en condiciones de precariedad. La paulatina recuperación en los niveles de empleo debilitó la base social de las organizaciones de desocupados y favoreció el fortalecimiento del poder sindical que fue promovido explícitamente por el gobierno al recomponer las negociaciones colectivas (paritarias) y los convenios colectivos de trabajo, a las instituciones encargadas de dictaminar los salarios y a las condiciones de trabajo conformadas por sindicatos, Estado y empresarios. Con esto el gobierno explicitaba su deseo de reinstitucionalizar la conflictividad social, incorporando algunas demandas y actores al sistema político formal y reencauzando las protestas callejeras más disruptivas por las vías de los canales institucionales. El mapa de los 
conflictos iría cambiando lentamente. Si en 2002 y 2003 las acciones de lucha las protagonizaban principalmente los desocupados, en los años posteriores fueron los trabajadores sindicalizados los que llevaron a cabo la mayor cantidad de protestas, en general mediante el formato habitual de la clase obrera: las huelgas (Antón, Cresto, Rebón \& Salgado, 2010; Etchemendy \& Collier, 2007). A pesar de que las luchas de una porción importante de los sectores populares continuaron en el margen de las instituciones - fundamentalmente las de los desocupados y los trabajadores del sector informal—, hacia mediados de la primera década del siglo xxi la conflictividad en Argentina había pasado de ser abiertamente callejera y disruptiva a ser mayormente institucionalizada y regulada (Antón et al., 2010).

Este proceso de "revitalización sindical" (Senén, 2011) no supuso un regreso al modelo gremial típico de la industrialización por sustitución de importaciones de los años de posguerra. Entre otras cosas, porque alcanzó solo a los trabajadores formales sindicalizados; mientras que un tercio de la población económicamente activa permaneció estructuralmente sin ingresar al mercado de trabajo registrado. Por esta razón a este patrón de negociaciones tripartitas se lo denominó neocorporativismo segmentado, en tanto se trató de "una modalidad de negociaciones a nivel de cúpulas en las cuales sindicatos, de carácter monopólico, asociaciones empresarias y el gobierno pactan un salario mínimo general y salarios sectoriales acordes a las metas de inflación, que se aplican sólo a una minoría sustancial de la fuerza de trabajo" (Etchmendy \& Collier, 2007, p. 149). El carácter segmentado de este modelo corporativista se basó en que el nuevo factor de poder y negociación sindical residía sobre todo en el sector registrado de la economía, dejando de lado a la gran masa de trabajadores que aún permanecían en condiciones precarias en el sector informal. A pesar de que entre los sindicatos primó una autonomía pragmática con respecto al gobierno (Etchemendy \& Collier, 2007), varios dirigentes ocuparon puestos en ministerios y en el parlamento durante esos años. La relación no sería lineal.

A pesar del renovado protagonismo de la conflictividad laboral, las luchas en Argentina no perdieron el carácter complejo y heterogéneo de los años noventa. Dos demandas impulsadas por distintos actores ocuparon un sitio privilegiado. En primer lugar, la demanda de justicia revinculada a la lucha contra la inseguridad estuvo vigente en todo el periodo. El gobierno rápidamente se había hecho cargo de uno de los reclamos históricos de los organismos de derechos humanos y derogó en los primeros meses de gobierno las leyes de impunidad que protegían a los dirigentes y cuadros medios protagonistas de delitos de lesa humanidad durante el gobierno militar. Sin embargo, los reclamos de justicia y lucha contra la impunidad habían cobrado nuevos significados hacia mediados de los años noventa, momento en que la inseguridad (el temor a ser 
víctima de un delito) se convirtió en una de las mayores preocupaciones de la sociedad argentina (Kessler, 2011; Pereyra, 2011). Sin dudas el momento protagónico de esta demanda en la discusión pública se dio a partir del secuestro y asesinato del hijo del empresario Juan Carlos Blumberg en marzo de 2004. La movilización que reclamaba justicia para este hecho y contra la inseguridad fue acompañada por más de doscientas mil personas en una de las concentraciones más masivas de entonces. A pesar de que el movimiento conducido por Blumberg disminuyó muy pronto, ${ }^{14}$ el gobierno recogió parte de los reclamos y endureció el código penal con una legislación más punitiva. La demanda de seguridad sería fuente de numerosas acciones colectivas —algunas violentas (Gamallo, 2017) — durante toda la década; incluso cuando la proporción de delitos violentos descendió (Kessler, 2011). En muchos casos, alrededor de la demanda de seguridad se aglutinaron identidades de carácter opositor: el propio Blumberg se presentó como candidato a gobernador de la provincia de Buenos Aires en 2007 por el derechista partido Frente Vamos, pero obtuvo apenas el $1.26 \%$ de los votos.

Por último, el siglo Xxi ha sido el siglo de la emergencia de las luchas socioambientales en Argentina. La propia lógica del modelo de desarrollo —en parte basada en actividades procesadoras de recursos naturales - ha provocado tensiones que se han reflejado en la conflictividad social. Así, pues, tanto la resistencia a la instalación de una mina de oro en Esquel en 2002 (lo cual se convirtió en un punto de inflexión en la memoria de las resistencias ambientalistas), como las protestas en la ciudad de Gualeguaychú, Entre Ríos, contra la instalación de fábricas de pasta celulosa en la margen uruguaya del río Uruguay, fueron las luchas emblemáticas del periodo. También se dieron numerosos conflictos a escala local: el de las comunidades indígenas por el reconocimiento de sus tierras, las denuncias de organizaciones campesinas ante las fumigaciones compulsivas, la resistencia al desmonte de tierras vírgenes con la pretensión de expandir la frontera agropecuaria, o las luchas urbanas por la contaminación de ríos o la relocalización de basurales (Merlinsky, 2013). La mayoría de estos conflictos involucraron procesos de organización autónomos y novedosos, como las asambleas ciudadanas de vecinos autoconvocados (Bottaro \& Sola, 2012). Estas organizaciones, en general, han recuperado la asamblea (herencia directa de las jornadas críticas de diciembre de 2001) como mecanismo político, propiciando la democracia directa como forma organizativa principal. El

14 Tal descenso se explica en parte por la "derechización” del discurso de Blumerg que diferenció las demandas de las víctimas de la inseguridad (víctimas legítimas, según su enfoque) respecto de las de la represión estatal, casos estos últimos en los que se ponía en cuestión la figura de víctima. Las sucesivas definiciones de Blumberg acotaron el universo simbólico de las protestas (Schilaggi, 2009). 
contenido asambleario de los movimientos ha reforzado, además, la autonomía de los colectivos frente a las empresas y el Estado en todos sus niveles y poderes. Por la propia dinámica de los conflictos estas fueron las organizaciones menos permeables al discurso gubernamental y, por lo mismo, las más opositoras e intransigentes. Así, si bien ciertas demandas han impactado en cambios institucionales, ${ }^{15}$ las referidas al medio ambiente han sido excluidas del sistema político y, en algunos casos, reprimidas (Costantino \& Gamallo, 2015).

\section{El conflicto entre el gobierno y la burguesía agropecuaria. Los movimientos sociales oficialistas y opositores (2008-2015)}

El gobierno de Néstor Kirchner que terminó en diciembre de 2007 no solo había cerrado la crisis político-institucional de la cual nació, sino que había conseguido construir una legitimidad propia en torno a una recuperación económica extraordinaria ${ }^{16}$ y la conformación de consensos sociales novedosos (Muñoz, 2008). Todo esto hizo que Cristina Fernández de Kirchner, esposa de Néstor, fuera electa como presidenta para el mandato 2007-2011. A pesar de que el mapa de la conflictividad social parecía continuar con las mismas características, un acontecimiento inusitado trastocaría la coyuntura política y el propio universo de las protestas sociales.

A comienzos de 2008, en un contexto de aumentos récord de los precios internacionales de los commodities, un proyecto gubernamental que intentaba aumentar las alícuotas ("retenciones") que pagaban las exportaciones de granos encontró una inesperada resistencia entre las cámaras patronales de dicho sector. La protesta de la Mesa de Enlace, el órgano que articulaba a las distintas organizaciones empresarias, se dio primero a través de lock-outs (cese de comercialización de los productos que originaron conatos de desabastecimiento), pero luego a través de la forma de lucha típica de los desocupados: el corte de rutas estratégicas a nivel nacional. Este hecho inédito marcó el escaso margen de influencia que sectores económicos históricamente dirigentes tenían en esa etapa sobre el Estado. La inesperada repercusión de este verdadero ciclo de protestas ${ }^{17}$ se debió a la férrea defensa corporativa de intereses sectoriales, pero

15 Los casos más conocidos son el nombramiento de la abogada de los ambientalistas de Gualeguaychú, Romina Picoloti, como secretaria de Ambiente y Desarrollo Sustentable del gobierno de Néstor Kirchner. En 2010, el gobierno de Cristina Kirchner aprobó la Ley de Glaciares, reclamada por los movimientos sociales.

16 Entre 2003 y 2007, el PBi creció un promedio anual de 8.68\%, según datos del Banco Mundial (2018b).

17 En 2008 las acciones públicas de estas organizaciones superaron en número a las de los trabajadores ocupados y las de los desocupados (Antón et al., 2010). 
también a la capacidad de articulación e interpelación que "El Campo" (como se denominó al bloque beligerante) logró ante un conjunto heterogéneo de grupos sociales, sectores económicos y fracciones políticas disconformes con el gobierno. ${ }^{18}$ Así, el conflicto se constituyó en una oportunidad política para que grupos opositores dispersos se reunieran en una identidad política común: el antikirchnerismo (Gamallo, 2013). Uno de los indicadores de esa articulación exitosa detrás del reclamo fue la aparición de movilizaciones masivas en los grandes centros urbanos del país que apoyaron a los productores y manifestaron su oposición abierta al gobierno. Se inauguraban en este periodo los "cacerolazos", una forma de protesta típica de las jornadas de diciembre de 2001 que los sectores medios y altos replicarían en reiteradas ocasiones para protestar contra los gobiernos kirchneristas.

El conflicto provocó la crisis política más importante desde diciembre de 2001 y obligó al gobierno a suspender transitoriamente la medida para que fuera aprobada por el Congreso Nacional. En los meses que duró el tratamiento parlamentario de la norma se movilizaron centenares de miles de ciudadanos en todo el país, ya sea manifestándose junto con el frente agropecuario, o apoyando a la alianza gobernante. La reacción ante las movilizaciones opositoras corrió a cargo de decenas de organizaciones sociales, piqueteras y sindicales que expresaron su aprobación del gobierno saliendo también a las calles. El rol de estas fue central para disputar el espacio público frente las convocatorias opositoras. A pesar de ello, la oposición logró reunir un consenso mayor en las calles que se reflejó en el parlamento. La norma se aprobó en la Cámara de Diputados, pero fue rechazada por el Senado: tras haber empatado en cantidad de votos, el vicepresidente desempató en contra del proyecto que su propio gobierno había impulsado.

El particular desarrollo del conflicto y los efectos de su resolución provocaron transformaciones relevantes y duraderas en el campo político y en el escenario de la conflictividad social. A partir de ese momento se produjo una polarización que se acentuaría a lo largo del tiempo: las confrontaciones tendrían casi inevitablemente al kirchnerismo como centro de gravedad, atraerían a numerosos actores sociales a su alrededor y construirían nuevos enemigos que se les opusieron desde distintos lugares. Tras la derrota, el gobierno perdió aliados en el peronismo (parte de su gabinete) y en el radicalismo hasta entonces oficialista. Asimismo, comenzó a resquebrajarse su alianza con algunos actores del poder económico, fundamentalmente los principales medios masivos de comunicación, que desde entonces serían fuertemente opositores. Estos factores,

18 "El campo somos todos" sería la frase que aglutinó consignas, demandas e identidades diversas (Retamozo \& Di Bastiano, 2017). 
sumados al estancamiento económico como reflejo de la crisis internacional iniciada en 2008, explican la derrota electoral del oficialismo en las elecciones de medio término de 2009.

A partir de allí el gobierno retomó la iniciativa política, radicalizando sus medidas y su discurso: nacionalizó los fondos de pensión privatizados en los años noventa, aplicó un subsidio cuasi universal a la niñez, promovió legislación antimonopólica para la regulación de los medios de comunicación, y aprobó la ley de matrimonio igualitario reconociendo derechos a las minorías sexuales. Estas medidas y la confrontación con varios de los actores más concentrados del poder económico atrajeron a nuevos sectores de la centro-izquierda, entusiasmados con la realización de un proyecto de gobierno soberano y popular. Dos hitos marcarían esta nueva etapa: los multitudinarios festejos por el bicentenario de la nación (que congregaron a más de dos millones de personas entre el 21 y el 25 de mayo de 2010) y el fallecimiento de Néstor Kirchner el 27 de octubre de $2010 .{ }^{19}$ Surgía un nuevo kirchnerismo, reconfigurado por confrontaciones inéditas, y fortalecido mediante una relación novedosa con los movimientos sociales. Terminaba de conformarse el kirchnerismo como una nueva identidad política con la que se identificaron amplios sectores de la población. Fundamentalmente a partir de la muerte de Kirchner miles de jóvenes en todo el país se sumaron a las organizaciones sociales oficialistas, especialmente a La Cámpora, agrupación con lazos orgánicos con el gobierno nacional (Vázquez \& Vommaro, 2012). Si bien el kirchnerismo sostuvo desde sus orígenes una disputa por la "calle", es decir, por sostener grandes niveles de movilización "propios", es en esta época cuando más se acentuarían sus rasgos movimentistas, aspirando a conducir no solo el Partido Justicialista, sino también a las organizaciones sociales identificadas con el oficialismo (Pérez \& Natalucci, 2010). Este afán por dirigir y subordinar a los movimientos sociales terminaría expulsando a muchas organizaciones del campo oficialista. Las agrupaciones kirchneristas — heterogéneas y en la mayoría de las veces con relaciones de competencia entre sí- sostuvieron el apoyo al gobierno participando con centenares de miles de personas en actos oficiales, celebraciones, conmemoraciones, festivales, etcétera. ${ }^{20}$

19 Durante los funerales del expresidente, cientos de miles de personas se reunieron en filas interminables para despedirlo.

20 Entre otros se destacan los actos del 25 de mayo, las concentraciones del 1 de marzo en el Congreso para celebrar el discurso presidencial en la apertura legislativa, las movilizaciones del 24 de marzo en repudio al último golpe de Estado cívico-militar, y las celebraciones del 10 de diciembre en conmemoración de la recuperación democrática. A estos deben sumárseles mítines de la militancia realizados esporádicamente en estadios de fútbol. Todos estos actos contaron con la masiva presencia de sindicatos, partidos y agrupaciones afines al gobierno y concentraron centenares de miles de personas en cada ocasión. 
Así, el universo de la movilización en Argentina comenzó a distinguir dos tácticas contrapuestas. Las acciones colectivas oficiales (protagonizadas por agrupaciones territoriales, partidos, sindicatos y un buen número de ciudadanos sin adscripción específica) intentaron ocupar las calles y plazas celebrando las conquistas del gobierno. A pesar de que hubo organizaciones que mantuvieron una relación conflictiva con el gobierno por la administración de recursos o por disputas políticas (Natalucci, 2012), la táctica general de las agrupaciones que se autodenominaron kirchneristas consistió en apoyar al gobierno en las confrontaciones con sus adversarios. En contraposición, agrupaciones opositoras salieron a las calles a luchar contra el gobierno para reivindicar medidas concretas. Dentro de ellas se evidenciaron marcadamente dos orientaciones políticas: por un lado, los movimientos sociales de izquierda con un horizonte anticapitalista continuaron sus luchas reivindicativas; por otro, los "movimientos sociales regresivos" (Antón et al., 2010), con una simbología y formas de participación totalmente distintas, salieron a las calles con consignas muy heterogéneas, pero con el objetivo explícito de luchar para horadar la experiencia kirchnerista y restaurar un orden conservador en Argentina.

En este escenario polarizado entre el antikirchnerismo (representado por los grandes medios de comunicación privados, los partidos conservadores y las movilizaciones regresivas) y las convocatorias oficialistas, las organizaciones populares no afines al gobierno — que tampoco se alinearon con la oposición de derechas - tropezaron con dificultades para encontrar un lugar de enunciación legítimo de sus reclamos. A pesar de ello, se mantuvo la conflictividad de las organizaciones piqueteras opositoras y de algunos sindicatos de base representados por extracciones de izquierda ortodoxa. Uno de estos episodios fue la ocupación del Parque Indoamericano, un predio abandonado en la zona sur de Buenos Aires. En los primeros días de diciembre de 2010 unas quince mil personas provenientes de asentamientos informales ${ }^{21}$ tomaron las tierras de dicho parque para protestar por las condiciones de hacinamiento en las que vivían y por la ausencia de políticas estatales en materia habitacional. El objetivo primordial de esta toma era, por un lado, comenzar a construir viviendas allí y, por otro, negociar una serie de medidas gubernamentales destinadas a resolver el problema de la vivienda de los que se habían organizado para protestar (Zapata, 2013). La respuesta a la toma por parte del gobierno nacional y local fue el desalojo violento del predio, reprimiendo con las fuerzas federales y locales. El conflicto en el Parque Indoamericano visibilizó la continuidad en asuntos de planeamiento urbano respecto del modelo neoliberal, en la medida en que las desigualdades urbanas (medios de transporte, acceso a la vivienda,

21 Las denominadas villas miseria, barrios populares similares a las favelas brasileras. 
etc.) se profundizaron, aun cuando el modelo de desarrollo se había transformado (Ciccolella, 2009; Guevara, 2014).

La recuperación económica de 2010-2011 y las iniciativas políticas que el gobierno retomó durante esos años le permitieron a Cristina Fernández de Kirchner reelegirse con el 54\% de los votos a fines de 2011 con una diferencia de casi 40\% respecto al segundo candidato más votado. Pero a mediados de 2012 las protestas emergieron en los barrios de clase media-alta de las principales ciudades del país, donde se convocaron - principalmente a través de las redes sociales- movilizaciones y "cacerolazos", es decir, concentraciones en las que la disconformidad con el gobierno de Cristina Fernández se mostraba golpeando cacerolas o haciendo ruido en la calle. Las primeras concentraciones espontáneas de ese año se dieron exclusivamente en Buenos Aires, agrupándose en algunas esquinas de los barrios en los que residen los sectores más acomodados de la ciudad. Las últimas fueron masivas y se produjeron en prácticamente todos los centros urbanos importantes del país con niveles de organización ascendentes, que incluyeron movilizaciones hacia edificios públicos. El detonante de estas protestas había sido la aplicación de nuevos controles a la compra de divisa extranjera; pero, como demuestran las entrevistas con los manifestantes (Pereyra, 2016), las demandas fueron diversas. Lo que articulaba la voluntad de protestar era precisamente el carácter opositor al gobierno en un contexto de fragmentación y dispersión de la oposición partidaria. Las protestas de 2012 fueron importantes porque comenzaron a perfilar en las calles el reagrupamiento que la oposición conservadora haría en el plano político años después.

Por otra parte, otro de los conflictos emblemáticos de la última gestión de Cristina Fernández ha sido el relativo al mundo sindical. La ruptura de la alianza con la CGT marcó el salto a la oposición de numerosos sindicatos que habían jugado un rol importante en la defensa del gobierno cuando las patronales agropecuarias provocaran la crisis política de 2008. Más allá de los reclamos puntuales de los gremios, ${ }^{22}$ el conflicto entre el gobierno y los sindicatos se explica, en parte, por la intención del primero de subordinar a los gremios y el objetivo de varios dirigentes sindicales de ocupar más espacios de poder en el Estado y en las candidaturas electorales (Gamallo, 2013). Durante el último mandato de Cristina Fernández, la CGT convocó a cinco paros generales de gran impacto; entre tanto las organizaciones sociales y piqueteras opositoras siguieron reclamando por la actualización de los montos de los subsidios estatales a emprendimientos productivos (Natalucci, 2012).

22 Entre otros, destaca la eliminación del "impuesto a las ganancias" a los trabajadores formales mejor remunerados.

100 L. Gamallo | La acción colectiva en Argentina: actores, demandas y formas de lucha desde el retorno democrático Perfiles Latinoamericanos, 28(55) | FLACso México | DOI: 10.18504/pl2855-004-2020 
Hacia fines del mandato de Cristina Fernández emergieron nuevas movilizaciones de sectores organizados como el movimiento de mujeres y su lucha contra el patriarcado expresada en la consigna "Ni una menos" y las movilizaciones del sector de trabajadores informales (que continuaba representando a un tercio del total de los asalariados en Argentina), a través de la creación de un organismo gremial en el que confluyeron diversas organizaciones previas: la Confederación de Trabajadores de la Economía Popular (стер). El movimiento de mujeres protagonizaría una movilización de más de trescientas mil personas el 3 de junio de 2015 en repudio de los femicidios y la violencia de género, y lograría la creación de un registro oficial de femicidios por parte del Poder Judicial.

A pesar de que el gobierno profundizó algunas medidas como la estatización parcial de Yacimientos Petrolíferos Fiscales, S. A. (YPF) en 2012 y la creación y/o aumento de subsidios a distintos sectores de la población, el modelo económico comenzó a mostrar signos de agotamiento evidentes y la mejora en los indicadores sociales se estancó (Kulfas, 2017). Confrontado con cada vez más sectores, el gobierno fue perdiendo lentamente el capital político que había obtenido con el contundente triunfo de 2011. Fue derrotado en las elecciones legislativas de 2013, luego de las masivas movilizaciones de 2012, y su candidato a presidente para las elecciones de noviembre de 2015, Daniel Scioli, perdió el balotaje contra el derechista Mauricio Macri, con lo que se inauguró una nueva etapa para los movimientos sociales argentinos.

\section{Los movimientos sociales ante un nuevo ciclo neoliberal en Argentina}

A pesar de que durante su campaña electoral Macri había prometido conservar buena parte de las medidas más progresivas del gobierno anterior, una vez en el poder demostró pronto que su objetivo era producir reformas regresivas: en los primeros meses de su gobierno produjo una marcada transferencia de ingresos desde los trabajadores a los sectores concentrados de la economía (Scaletta, 2017). En este sentido, las elecciones de 2015 no solo representaron una alternancia democrática, sino que marcaron un cambio en el modelo de desarrollo previo. ${ }^{23}$ Lo particular de esta situación es que este cambio se produjo sin que ocurriera ninguna crisis económica, social o política que justificara la reorien-

23 Scaletta (2017) resume las transformaciones de estos dos años del siguiente modo: $i$ ) liberalización del comercio exterior y de capitales; ii) redolarización de las tarifas de los servicios públicos y su consecuente aumento; iii) baja generalizada de los salarios (vía aumentos de precios), y iv) el inicio de un nuevo ciclo de endeudamiento externo. 
tación. Si bien durante los últimos años del gobierno de Cristina Fernández el modelo había mostrado signos indiscutibles de agotamiento, ninguno de los indicadores sociales y económicos permitía diagnosticar una crisis hacia 2015. ${ }^{24}$ Por esta razón, para la administración de Macri aplicar medidas de ajuste fiscal y ortodoxia económica no está resultando sencillo. Desde la asunción en diciembre de 2015 y el anuncio de miles de despidos en la administración pública a fines de ese mes, las resistencias a las políticas gubernamentales se han multiplicado en todos los planos. El cambio de gobierno transformó los clivajes de las organizaciones sociales: lentamente el centro de gravedad político ha rotado desde el kirchnerismo hacia el macrismo. Las viejas alianzas o fracturas se han reconfigurado en este nuevo escenario, en el que también se ha modificado la política estatal hacia la acción colectiva, en la medida en que Macri ha promovido una campańa de desprestigio acompañada de una represión selectiva pero creciente de la protesta social.

A pesar del poco tiempo transcurrido, es posible delimitar algunos cambios y continuidades de la acción colectiva respecto del periodo previo. Teniendo en cuenta los sujetos, el movimiento obrero nucleado en la CGT parece retomar el protagonismo de los conflictos sociales. Dicha central inició un proceso de unidad durante 2016, aunque con tensiones: un sector blando tolera las políticas gubernamentales, mientras que otros gremios (paradójicamente los que enfrentaron también a Cristina Kirchner) se muestran más combativos. Los dos grupos han protagonizado dos grandes huelgas generales en 2017; mientras que algunos sectores específicos, como los docentes y estatales, realizaron masivas movilizaciones y huelgas que en algunos casos fueron exitosas. Son precisamente los trabajadores estatales (tanto del ámbito educativo como del administrativo) los que más han resistido los despidos o congelamientos salariales. Las masivas movilizaciones de los docentes han conseguido buenos acuerdos salariales en 2017; mientras que la atomización y debilidad de los trabajadores estatales ha impedido frenar los miles de despidos en la administración pública nacional. Por otra parte, la ya mencionada CTEP, que agrupa a los trabajadores informales, ha tenido un gran protagonismo, manifestándose en diversas oportunidades y logrando la promulgación de la Ley de Emergencia Social que, entre otras cosas, creó un registro de trabajadores informales y les otorga un seguro de salud público. En continuidad con los últimos años del periodo previo, el movimiento de mujeres protagonizó movilizaciones masivas realizando un paro y una masiva movilización el 8 de marzo de 2017. Las luchas por el reconocimiento de derechos de las mujeres han sido centrales en el mapa de la conflictividad social. En especial durante los últimos años han conseguido instalar en la agenda pú-

24 Según el Banco Mundial (2018b), entre 2011 y 2015 el PBI creció en promedio 1.8\% anual. 
blica, entre otros temas, la discusión por la despenalización del aborto. ${ }^{25}$ Una de las demandas que reemergió con fuerza en este periodo es la vinculada a los derechos humanos. Esto se debe, en primer lugar, a la restauración del clima de impunidad que favorece a los responsables del genocidio de la última dictadura cívico-militar. Sobresale una multitudinaria marcha del 10 de mayo de 2017 que provocó que se diera marcha atrás en la aplicación de una sentencia de la Corte Suprema que beneficiaba a los militares y civiles condenados por delitos de lesa humanidad cometidos durante la última dictadura reduciéndoles la pena. En segundo lugar, por la escalada represiva que ha incluido casos resonantes de violencia institucional como la muerte de los militantes Santiago Maldonado y Rafael Nahuel y el asesinato de jóvenes de barrios populares.

Algunas demandas puntuales han articulado sectores heterogéneos que han salido a la calle unidos alrededor de una reivindicación puntual. Fue el caso de las protestas que se produjeron en diciembre de 2017 contra la reforma previsional que supuso una rebaja en las jubilaciones y pensiones mínimas. A pesar de que el proyecto de ley fue aprobado en el Congreso, la masividad y unión de diversos sujetos contenciosos, así como la radicalización del reclamo — que incluyó virulentos episodios de violencia colectiva - obligaron a retroceder al gobierno con su proyecto de reforma laboral, lo que ha dejado un escenario político abierto hacia el futuro.

\section{Palabras finales}

El campo de la conflictividad social en Argentina se ha transformado de modo importante desde el retorno a la democracia en 1983. Más allá de los cambios y continuidades respecto de los periodos previos que hemos identificado en las diversas etapas, a nivel general es posible afirmar que en las últimas décadas la acción colectiva se expandió a múltiples actores, canalizó mayores demandas, y se amplió en sus formas de manifestación. Este proceso de heterogeneidad y complejización de la conflictividad — que comenzó tras la última dictadura militar, pero que se intensificó desde finales de los años noventa— parece ser irreversible, dada la propia complejidad que atraviesa a los sectores populares y a las clases medias en sus distintas inserciones laborales, identitarias y políticas.

Debido a los efectos de esta ampliación de la protesta social, la acción colectiva en Argentina ha formado parte de la vida político-institucional del país con mayor intensidad, fundamentalmente desde el ciclo de protesta que terminó con

25 Mientras terminamos este artículo, en marzo de 2018, el Congreso empezaba a discutir un proyecto de ley de interrupción voluntaria del embarazo. 
el modelo neoliberal a comienzos del siglo xxi. Una de las especificidades de la democracia argentina es la relevancia de la movilización callejera: esto es lo que hace a Argentina un país en particular movilizado. En este sentido, así como no es posible comprender la irrupción del kirchnerismo sin hacer inteligibles a los movimientos sociales que impugnaron el orden neoliberal y, en parte, lo hicieron posible, es evidente que la experiencia de doce años de gobierno posneoliberal transformó de manera radical a los movimientos sociales argentinos. No solo los fragmentó aún más en función de su apoyo u oposición al gobierno, replanteando sus tácticas y modos de organización, sino que también estructuró un nuevo campo de confrontación política en torno al Estado y, específicamente, al gobierno kirchnerista. Esto se explica en parte por el surgimiento de numerosas organizaciones sociales oficialistas y la emergencia, durante esos años, de movimientos sociales con una gramática conservadora, tanto por la pertenencia de clase de los movilizados como por sus consignas y formas de movilización. El resurgimiento de las masivas convocatorias de los "movimientos sociales regresivos" (Antón et al., 2010) en 2012, ante la fragmentación de la oposición político-partidaria, explica una porción de la articulación lograda años después detrás de la candidatura de Mauricio Macri.

La victoria de un gobierno neoconservador en 2015 abrió un nuevo campo de confrontaciones en el que las viejas rupturas o alianzas se empiezan a reconfigurar. El desafío para las organizaciones populares de construir tácticas en común ante la heterogeneidad descrita ha sido alcanzado en la resistencia a políticas públicas concretas que amenazan con hacer retroceder derechos sociales. En este punto los movimientos sociales parecen estar, una vez más, un paso adelante de la dirigencia política argentina. Los próximos años marcarán hasta dónde puede avanzar el gobierno con sus planes de reformas estructurales. Acerca de esto la dinámica de la acción colectiva tendrá bastante qué decirnos.

\section{Referencias}

Anderson, P. (1997). Balance del Neoliberalismo: lecciones para la izquierda, Procesos, (11), 111127. doi:10.29078/rp.v1i11.367

Andrenacci, L., Ikei, L., Mecle, E. \& Corvalán, A. (2005). La Argentina de pie y en paz: acerca del Plan Jefes y Jefas de Hogar de Desocupados y del modelo de política social de la Argentina contemporánea. En L. Andrenacci (Comp.), Problemas de politica social en la Argentina contemporánea (pp. 181-211). Buenos Aires: Prometeo.

104 - L. Gamallo | La acción colectiva en Argentina: actores, demandas y formas de lucha desde el retorno democrático Perfiles Latinoamericanos, 28(55) | FLACso México | DOI: 10.18504/pl2855-004-2020 
Antón, G., Creto, J., Rebón, J. \& Salgado, R. (2010). Una década en disputa. Apuntes sobre las luchas sociales en la Argentina. OSAL, (28), 95-116.

Arakaki, A. (2011). La pobreza en Argentina 1974-2006: construcción y análisis de la información. Buenos Aires: Universidad de Buenos Aires.

Arditi, B. (2009). El giro a la izquierda en América Latina: ¿una política post-liberal? Ciências Sociais Unisinos, 45(3), 232-246. doi:10.4013/csu.2009.45.3.06

Auyero, J. (2002). Los cambios en el repertorio de la protesta social argentina. Desarrollo Económico, 42(166), 187-220. doi:10.2307/3455940

Azpiazu, D., Basualdo, E. \& Khavisse, M. (2004). El nuevo poder económico en la Argentina de los años 80. Buenos Aires: Siglo XXI.

Banco Mundial. (2018a). Recuperado de https://datos.bancomundial.org/indicador/FP.CPI .TOTL.ZG?end=2013\&locations=AR\&start $=1960 \&$ view $=$ chart

Banco Mundial (2018b). Recuperado de https://datos.bancomundial.org/indicador/NY.GDP .MKTP.KD.ZG?locations=AR

Basualdo, E. (2011). Sistema político y modelos de acumulación. Tres ensayos sobre la Argentina actual. Buenos Aires: Atuel.

Bottaro, L. \& Sola Álvarez, M. (2012). Conflictividad socioambiental en América Latina. El escenario post-crisis de 2001 en Argentina. Política y Cultura, (37), 159-184.

Cantamutto, F. \& Costantino, A. (2016). El modo de desarrollo en la Argentina reciente. Mundo Siglo XXI, XI(39), 15-34.

Cantamutto, F. \& Wainer, A. (2103). Economía politica de la convertibilidad. Buenos Aires: Capital Intelectual.

Ciccollela, P. (2009). Buenos Aires: una metrópolis postsocial en el contexto de la economía global. En P. Pírez (Ed.), Buenos Aires, la formación del presente. Quito: OLACHI.

Costantino, A. \& Cantamutto, F. (2017). Neodesarrollismo, el programa de la industria ante la crisis neoliberal. Márgenes, III (3), 9-26.

Costantino, M. A. \& Gamallo, L. (2015). Los conflictos socioambientales durante los gobiernos kirchneristas en Argentina. En L. D. Vázquez (Comp.), De la democracia liberal a la soberania popular: articulación y crisis en América Latina (pp. 277-308). México: Flacso México.

L. Gamallo | La acción colectiva en Argentina: actores, demandas y formas de lucha desde el retorno democrático Perfiles Latinoamericanos, 28(55) | Flacso México | DoI: 10.18504/pl2855-004-2020 
Etchemendy, S. \& Collier, R. (2007). Golpeados, pero de pie. Resurgimiento sindical y neocorporativismo en Argentina (2003-2007). Politics and Society, 35(3), 145-192. doi:10.1177/ 0032329207304318

Farinetti, M. (2000), Violencia y risa contra la política en el Santiagueñazo. Apuntes de Investigación del CECyP, (6), 77-126.

Gaggero, A. \& Wainer, A. (2004). Burguesía Nacional-Crisis de la convertibilidad: el rol de la UIA y su estrategia para el (tipo de) cambio. Realidad Económica, (204), 14-41.

Gamallo, L. (2013). Entre paros y cacerolazos: apuntes sobre la conflictividad social en la Argentina reciente. En Anuari del conflicte social 2012/Anuario del conflicto social 2012 (pp. 877-908). Barcelona: Observatorio del Conflicto Social.

Guevara, T. (2014). Transformaciones territoriales en la Región Metropolitana de Buenos Aires y reconfiguración del régimen de acumulación en la década neo-desarrollista. QUID, 16(4), 115-136.

Kulfas, M. (2017). Los tres kirchnerismos. Una historia de la economía argentina 2003-2005. Buenos Aires: Siglo XXI.

Kessler, G. (2011). El sentimiento de inseguridad: sociología del temor al delito. Buenos Aires: Siglo XXI.

McAdam, D. (1999). Orígenes terminológicos, problemas actuales y futuras líneas de investigación. En D. McAdam, J. McCarthy \& M. Zald (Eds.), Movimientos sociales: perspectivas comparadas (pp. 49-70). Madrid: Ístmo.

McAdam, D., McCarthy, J. \& M. Zald (1999). Oportunidades políticas, estructuras demovilización y marcos interpretativos culturales. En D. McAdam, J. McCarthy \& M. Zald (Eds.), Movimientos sociales: perspectivas comparadas (pp. 21-46). Madrid: Ístmo.

Merklen, D. (2010). Pobres ciudadanos: Las clases populares en la era democrática (Argentina, 19832003). Buenos Aires: Gorla.

Merlinsky, G. (2013). Introducción: la cuestión ambiental en la agenda pública. En G. Merlinsky (Comp.), Cartografias del conflicto ambiental en Argentina (pp. 19-60). Buenos Aires: Fundación ciccus.

Muñoz, M. A. (2010). Sisifo en Argentina. Orden, Conflicto y Sujetos Politicos. Villa María: EDuvim/Plaza y Valdés. 
Muñoz, M. A. \& Retamozo, M. (2008). Hegemonía y discurso en la Argentina contemporánea: Efectos políticos de los usos de "pueblo" en la retórica de Néstor Kirchner. Perfiles Latinoamericanos, 16(31), 121-150.

Natalucci, A. (2012). Políticas sociales y disputas territoriales: El caso del programa "Argentina Trabaja". Revista Perspectivas de Políticas Públicas, 2(3), 126-147. doi:10.18294/rppp.2012.614

Pérez, V. \& Rebón, J. (2012). Las vías de la acción directa. Buenos Aires: Aurelia Rivera.

Pérez, G. \& Natalucci, A. (2010). La matriz movimentista de acción colectiva en Argentina: La experiencia del espacio militante kirchnerista. América Latina Hoy, (54), 97-112.

Perelmiter, L. (2012). Fronteras inestables y eficaces. El ingreso de organizaciones de desocupados a la burocracia asistencial del Estado. Argentina (2003-2008). Estudios Sociológicos, XXX(30), 431-458.

Pereyra, S. (2016). La estructura social y la Movilización. Conflictos políticos y demandas Sociales. En G. Kessler (Comp.), La sociedad argentina hoy. Radiografia de una nueva estructura (pp. 233-255). Buenos Aires: Siglo XXI.

Pereyra, S. (2011). ¿La lucha es una sola? La movilización social entre la democratización y el neoliberalismo. Buenos Aires: Biblioteca Nacional/Universidad Nacional General Sarmiento.

Retamozo, M. (2011). Movimientos sociales, política y hegemonía en Argentina. Polis, 10(28), 243-279. doi:10.4067/S0718-65682011000100014

Retamozo, M. \& Batistiano, R. (2017). Los movimientos sociales en Argentina. Ciclos de movilización durante los gobiernos de Néstor y Cristina Kirchner 2003-2015. Cuadernos del CENDES, 34(95), 117-153.

Scaletta, C. (2017). La recaída neoliberal: la insustentabilidad de la economía macrista. Buenos Aires: Capital Intelectual.

Schillagi, C. (2009). La disputa de las víctimas. "Inseguridad", reclamos al Estado y actualización pública de organizaciones y familiares de víctimas de delitos en Argentina (2004-2006). Ponencia presentada en I Congreso Nacional "Protesta Social, Acción Colectiva y Movimientos Sociales", Buenos Aires.

Schuster F., Pérez G., Pereyra S., Armesto M., Armelino, M., García, A., Natalucci, A., Vázquez, M. \& Zipcioglu, P. (2006). Base de datos sobre protestas sociales en Argentina.1989-2003. [Grupo de Estudios sobre Protesta Social y Acción Colectiva, Instituto de Investigaciones Gino Germani, Universidad de Buenos Aires]. Argentina.

L. Gamallo | La acción colectiva en Argentina: actores, demandas y formas de lucha desde el retorno democrático Perfiles Latinoamericanos, 28(55) | FLACso México | DoI: 10.18504/pl2855-004-2020 
Senén González, C. (2011). La revitalización sindical en Argentina durante los Kirchner. Revista Trabajo, 5(8), 39-64.

Svampa, M. (2005). La sociedad excluyente: La Argentina bajo el signo del neoliberalismo. Buenos Aires: Taurus.

Svampa, M. \& Pereyra, S. (2003). Entre la ruta y el barrio: La experiencia de las organizaciones piqueteras. Buenos Aires: Biblos.

Tarrow, S. (1997). El poder en movimiento. Los movimientos sociales, la acción colectiva y la politica. Madrid: Alianza.

Tilly, Ch. (2000). Acción colectiva, Apuntes de Investigación del CECyP, (6), 9-32.

Tilly, Ch. (1978). From Mobilization to Revolution. Nueva York: Random House.

Vázquez, M. \& Vommaro, P. (2012). La fuerza de los jóvenes: aproximaciones a la militancia kirchnerista desde La Cámpora. En G. Pérez \& A. Natalucci (Eds.), Vamos las bandas. Organizaciones y militancia kirchnerista (pp. 149-174). Buenos Aires: Nueva Trilce.

Villarreal, J. (1985). Los hilos sociales del poder. En E. Jozami, P. Paz \& J. Villarreal, Crisis de la dictadura argentina. Política económica y cambio social (1976-1983) (pp. 197-283). Buenos Aires: Siglo XXI.

L. Gamallo | La acción colectiva en Argentina: actores, demandas y formas de lucha desde el retorno democrático Perfiles Latinoamericanos, 28(55) | FLACSO México | DoI: 10.18504/pl2855-004-2020 